\title{
Particularity as Paradigm: A Wittgensteinian Reading of Hegel's Subjective Logic
}

\begin{abstract}
I provide a distinctively Wittgensteinian interpretation of Hegel's Subjective Logic, including the parts on the concept, the judgement and the syllogism. I argue that Wittgenstein implicitly recognised the moments of universality, particularity and individuality; moreover, he was sensitive to Hegel's crucial distinction between abstract and concrete universals. More specifically, for Wittgenstein the moment of particularity has the status of a paradigmatic sample which mediates between a universal concept and its individual instances. Thus, a concrete universal is a universal that includes every individual via its paradigmatic sample. Next, I provide a generic account of the emergence of concrete universals through a series of negations that follows the basic structure of Hegel's judgement- "the individual is the universal"-and the syllogism - "the individual is the universal mediated by the particular". This development is illustrated with examples from Hegel (a plant, Socrates, Caesar, a Stoic sage, Jesus) as well as from Wittgenstein (colour samples, the standard metre, works of art). I take Wittgenstein's argument against private language as implying that we cannot do without paradigms in our epistemic practices. If the conclusion of the section "Subjectivity" in Hegel's Science of Logic is that the moment of particularity cannot be ignored or dispensed with, then it would mean that we cannot do without paradigms in our epistemic practices: that is, that private rules are impossible.
\end{abstract}

\section{Paradigm in Wittgenstein}

This essay is about finding parallels, affinities and points of contact between Hegel and Wittgenstein. Let me begin with Wittgenstein or, rather, with my own interpretation of something I have taken from Wittgenstein: namely, what I call paradigmatic thinking, i.e. epistemic activities involving paradigms. Let a paradigm of $\mathrm{X}$ be a material object together with the praxis of applying this object in a given situation. I call the object of a paradigm a paradigmatic sample. "Object" is meant very broadly here (e.g. in a Quinean sense as a spatio-temporal hunk of matter). Paradigmatic samples are real material things ranging from clearly defined objects like the metre stick or a colour plate to intricate structures 
like formalisations of mathematical proofs or works of art. A paradigmatic sample is a model of a situation (what Wittgenstein called "model" in his early notebooks and "image" [Bild] in the Tractatus). A paradigm is, thus, a model together with a method for its projection or rather comparison. A paradigm of X is a praxis that involves material objects (it is not important whether there is a single object or several); it is a method for deciding whether a given object is X. This is typically done by comparing the paradigmatic sample with the given object. This may be done indirectly, e.g. X may be defined by (with reference to) $\mathrm{Y}$ which is in turn defined by reference to a paradigmatic sample.

Wittgenstein wrote on many occasions that colour concepts and standards of measure are introduced by means of paradigmatic samples (the standard sepia and the standard metre). The same is true of numerals, i.e. concepts for numbers. We can give meaning to the numeral 3 using the following definition: "The list || | means 3." The list || | serves in this sense as a yardstick. The numeral 3 is a substitution or, rather, an abbreviation for the list || |. I argued in my book Wittgenstein on Internal and External Relations (2015) that the same scheme applies in a number of other domains. There are for example paradigmatic mathematical proofs and paradigmatic works of art (Wittgenstein calls them "tremendous"). Furthermore, the standard of length can be introduced and defined by a paradigmatic sample (e.g. the standard metre in Paris) or with the help of other physical constants (e.g. the speed of light) which are ultimately defined by paradigmatic samples (e.g. a beam of light).

\section{Rule-following}

Wittgenstein did not claim that this scheme is universal, i.e. that every concept is introduced by a paradigm which refers to a paradigmatic sample. I would like to put forward the claim-which I am aware is controversial-that Wittgenstein's discussion of private language supplies the argument that we cannot do without paradigmatic samples. Wittgenstein pointed out that the idea of a private rule is inconsistent. There has been a long debate about what "private" actually means here. If we take "private" to mean "not referring to any external object" (like naming my sensation S), the desired conclusion would then follow: A private rule-following is a rule-following without the recurrence to any paradigmatic sample.

Of course, this argument is only sketched in broad outline. However, it is enough to allow us to draw a connection to Hegel's logic. If the conclusion of the section "Subjectivity" in Hegel's Science of Logic is that every object is the unity of the singular, the particular and the universal, or, more specifically, 
that the moment of particularity cannot be ignored or dispensed, then it would mean, on my interpretation, that we cannot bypass paradigms in our epistemic practices, i.e. that private rules are impossible. Let us, therefore, examine how Hegel's subjective logic can be employed in support of Wittgenstein's argument against private language.

\section{Paradigms in Hegel's subjective logic}

The main claim I want to advance is that a similar structure is to be found in Hegel's subjective logic. In my interpretation, I bring Hegel's notion of the subject closer to Wittgenstein's notion of the linguistic community. Subjective logic, then, becomes the logic of language-games or, more broadly, grammar in Wittgenstein's idiosyncratic sense. For Hegel, the concept [Begriff] is not merely the fundamental structure of our thinking, but rather a form that warrants the speculative identity of thought and being. Hegel recognises three basic moments of the concept: universality, particularity and singularity (individuality). ${ }^{1}$ Hegel's account of the concept consists of a dialectical movement from universality to particularity and finally to individuality. Hegel also begins his dialectical account of the concept with-it must be stressed-abstract universality. Universality is something that is already available from the logic of essence. Abstract universality is something presupposed. We find an analogous presupposition in Wittgenstein's discussion of the ostensive definition, where he stresses that the place of the defined expression or its role in grammar must be already prepared (PI: §31) in order to carry out an ostensive definition. So, for instance, exclaiming "From now on, this colour shall be called 'sepia'!” and pointing at a colour plate presupposes that we already know what colour is. Colour is a grammatical category in Wittgenstein and an abstract universal in Hegel (E I: §163).

Abstract universality or general conception (allgemeine Vorstellung) is characterised by neglecting particular features which would account for specific differences among the subspecies and individuals that fall under the concept in question. What, then, is particularity? The traditional (Leibnizian) view of particularity is that of a subspecies or a subset (cf. Stekeler-Weithofer 1992: p.350). Hegel, however, finds this view too narrow and thus unsatisfactory. Particularity

1 In this essay I will render the German expression "einzeln" and its cognates as "singular" or "individual" depending on the context of the translation. Di Giovanni prefers "singular" (SL 2010: p.lxx), Pinkard "singular" or "singular individual" (PS 2018: p.476), Brinkmann and Dahlstrom "singular" (EL 1830/2010). I do not reserve "individual” exclusively for personal individuality as Di Giovanni does (SL 2010: p.lxx). 
is the determinateness (Bestimmtheit) of the concept. The determinateness of universality is its difference. It is its outward difference, i.e. the difference between the universal and the particular. The particular is thus a negation of the universal. Hegel says: "the determinateness of the particular is simple as principle, but it is also simple as a moment of the totality, determinateness as against the other determinateness." (SL 2010: p.532) Particularity is hence the principle of difference-the difference within the universal concept which is differentiated into subspecies and constituent elements.

\section{Two interpretations of particularity}

Understanding Hegel's account of particularity has proven to be anything but straightforward. Hegel probably adopted his conception of particularity from Gottfried Ploucquet, who was active at the time of Hegel's studies in Tübingen. Ploucquet distinguished between "exclusive" and "comprehensive" particularity. An exclusive particular A is an instantiation of A. For example, what is meant by the expression "this particular tree" is this tree as opposed to that particular tree over there. This is why this use of particularity is exclusive. Comprehensive particularity, in contrast, does not exclude any singular instance of the term in question. If exclusive particularity is instantiation, then this kind of particularity comes closer to singularity (even "some trees" is understood in a nominalist sense as, say, "this tree, that tree and that tree over there"). ${ }^{2}$ Then, however, the crucial question remains: how are we to understand comprehensive particularity, that is, the true particularity?

Arguably, this distinction between exclusive and comprehensive particularity aligns with two main contemporary interpretations of particularity. On the first interpretation, the particular is a (comprehensive) perspective on a universal concept. In Žižek's words: "the true particularity is, primarily, the particular subjective position from which the universal Notion [concept] is acceptable to me" (2012: p.360). A particular is a specific historical appearance of a universal. On the second interpretation, the particular is an undifferentiated example (that

2 See Redding (2014) for a thorough discussion of this issue. He argues that "Ploucquet's 'exclusive' use would correspond to the quasi-naming role of the subject term in its immediacy, but as the properly logical form of the expressed judgement gets redetermined in different functional contexts it gets the properties of Ploucquet's 'comprehensive' sense of particularity." (2014: p.293) 
is, an instantiation). This interpretation was advocated by Goethe, ${ }^{3}$ and more recently by Winfield. ${ }^{4,5}$ The problem with the first (comprehensive) interpretation is that it does not account for the difference within the universal concept. The only difference available is that between different subjective and historical perspectives on the universal concept. The particular is, however, the (first) negation of the universal; it is something that the universal is not (Winfield 2011: p.233). A subjective position on something is not necessarily its negation. The problem with the second interpretation is that an example always exemplifies either too little or too much. Examples are either too imperfect to capture an ideal universality or else, possibly at the same time, exemplify features that do not belong to the universal concept. ${ }^{6,7}$ The problem here is that we lack a perspective (Wittgenstein would say a method of projection) on the example that would determine what exactly is being exemplified. Examples thus lack the determinateness of the particular.

We can understand particularity as a process of mediation that goes from universality to singularity (as the development of the predicate in the abstract judgement; see below). In comprehensive particularity, the process, so to speak, has not started yet, whereas exclusive particularity is a result of this process. Comprehensive particularity is too universal, exclusive particularity too singular.

3 "[A] particular [is] considered only as an illustration, as an example of the universal", Maxims and Reflections, cited in Žižek (2012: p.97).

4 "As particular, each instance of the shared quality comprises an undifferentiated example, standing in an identical relation to the quality they hold in common." (Winfield 2006: p.76) 5 The example view of particularity is supported in the "Sense-certainty" chapter of the Phenomenology of Spirit. There, Hegel distinguishes between essence and example. This distinction is further linked to that between immediacy and mediation (PdG: p.83). Cf. Warminski (1986: p.177): "That 'an actual sense-certainty is not only this pure immediacy, but an example (Beispiel) of it' means both 'by-play'-particular, inessential and so on-and 'example' as it later appears in the text (and as in its 'normal' usage)."

6 For Žižek (2012: p.364) this too little and too much marks the difference between the idealist and materialist use of examples.

7 Exemplifying too much is captured in the German "Bei-spiel", which Hegel links to "beiherspielen" (PdG: p.83). Terry Pinkard renders this verb as "there is a good deal more in play" (PS 2012: Ф|92). 


\section{Particular as paradigm}

My proposal is, so to speak, a synthesis of these two accounts of particularity, with a focus on the actual mediation. I propose to take the particular as the paradigm. Remember that a paradigm is a material object (paradigmatic sample) together with the praxis of its application. A paradigmatic sample of $X$ is (also) an example of $\mathrm{X}$ while, at the same time, a paradigmatic sample is different from an example (more about the difference later). What paradigms do share with examples is that a paradigm is different from the universal concept-or more precisely: a paradigm is different from abstract universality. Furthermore, an integral part of a paradigm is the praxis of comparing the paradigmatic sample with other objects or situations. This practical trait provides the particular with its determinateness, with the principle of difference. As paradigm, the particular is a principle. This praxis is always rooted in a specific social and historical context. For Hegel, the particular is also universal and individual. Every paradigm has an individual aspect, which is the paradigmatic sample, and also a universal aspect, which is the universal dimension of the concept.

Individuality is the negation of particularity (or the negation of the negation of universality). The paradigm is a principle, a method (of comparing the paradigmatic sample with other objects). The negation of particularity can be expressed as the determinate determinateness (SL: \$1343). For an abstract method (which can be applied on many occasions) is now a concrete application of this method which has a concrete outcome: the individual that belongs to the universal concept.

Wittgenstein was worried that philosophical problems and paradoxes arise when a word or a word-sequence is taken out of its context of use. The context of use means not only a linguistic context (i.e. the surrounding text), but also an extra-linguistic context, i.e. the praxis with the linguistic expression which involves paradigms. The context of use is thus a particularisation of a linguistic expression. This is not surprising. Utilising the points elaborated above, we can attempt a stronger interpretation: neglecting the particular moment, neglecting the context of use, means in fact treating language as something abstract. Ultimately it means failing to consider paradigmatic samples in rule-following practices, which amounts to private rule-following.

We are now in a better position to characterise the two conceptions of universality, abstract and concrete. Abstract universality is devoid of any reference to a paradigmatic sample. As Badiou says in an anti-Hegelian vein: "all true universality is devoid of a center." (2003: p.19) In contrast, concrete universality-in Žižek's words-"bears witness to a scar in some particularity, and remains al- 
ways linked to this scar" (2012: p.362). This centre, this scar, is a paradigmatic sample. ${ }^{8}$

\section{Judgement}

Let us now turn to the next stage of Hegel's development of his subjective logic. The concept in its posited particularity is a judgement. First, I shall discuss judgement in its abstract form: "The individual is the universal" or "The subject is the predicate"; further development of the judgement will be addressed later. The subject is the immediately concrete universal and the predicate is the abstract universal. In the judgement, both sides are being developed, in order to reach a perfect identity which is expressed by the copula "is". The predicate is developed from the abstract universality to the particularity, i.e. to a paradigm. The subject is developed from its immediate individuality into the particularity that is already contained, as such, in the individual, just as a seed already contains the essence of the plant. In the judgement "This rose is red", this individual rose, which contains many particular determinations, e. g. colour, aroma, length, is developed by negation into one of them, the colour. Analogously, the abstract universal "red" is developed, again by negation, into its paradigm. Now, a perfect identity can be achieved when the rose is compared with the paradigmatic sample of red with respect to their colour. The particularised individual is identical with the paradigmatic sample. They can exchange their roles: the particularised individual can become a paradigmatic sample of the original universal (and further, by the negation of the negation, the universal) and the original paradigmatic sample can become, again by negation, a mere instance of the universal. This is the exchange of meanings that happens in the judgement (E I: $\S 196)$.

On the subject side of the judgement, there is an inverse development from individuality to particularity and then to universality. While the development captured by the succession from universality through particularity to individuality presents a series of presuppositions (particularity presupposes universality and individuality presupposes particularity), the development from individuality through particularity to universality can be taken as a development of an idea and as a real, even historical process in space and time. As we know, the concept

8 Paul Redding suggested to me the term "witness" instead of "scar", which has negative psychoanalytic connotations. A paradigmatic sample is a kind of witness to a judgement. There is an interesting association with Wittgenstein's discussion of the so-called private language argument. A private language would be deprived of this witness. 
is for Hegel the fundamental structure of thinking and reality. Hegel provides a great many examples. I have already mentioned the seed that discloses itself into a plant and further into its species. Hegel comments: "the seed discloses itself, something which is to be considered the judgment of the plant." (EL 1830/2010: p.242; E I: §166) The growing of a plant is a real process that, however, does not involve thinking or language. Before proceeding to higher and more complex processes, it has to be noted that if thinking and language are involved in the judgement, the subject, the immediately concrete, is initially an empty name (E I: §169), or as we would say nowadays, a singular term or proper name. ${ }^{9}$ What we are looking for is the development from a proper name (individuality) to a paradigm (particularity) and further to a universal term.

\section{Caesar}

Hegel discussed Caesar's life and his significance in history on many occasions. Let us now turn to Hegel's Lectures on the Philosophy of History (PGh: pp.37980). Initially, Caesar was the name of an individual. ${ }^{10} \mathrm{He}$ acted in a particular way-militarily and politically - that was hostile to the Roman Republic, which was an empty name at that time. After he nominally assumed sovereign power-became dictator for life-the republic was on the verge of collapse. By his assassination, the conspirators hoped to restore the republican regime. But the opposite happened: they precipitated the end of the republic. "Caesar", a familial name, was changed into the title of the Roman emperors. ${ }^{11}$ This title then passed into many European languages (English is an exception) as the universal concept designating the role of an emperor (e.g. "Kaiser" in German, "czar” in Russian, "císař” in Czech). What we have here is a transition from the individual (Julius Caesar as a person) to the particular (Caesar's military and political way of acting) to the universal (Caesar as a title and a caesar as

9 In this connection, Agamben clearly recognises that there are two modes of precedence-presupposition and time precedence: "In the name (in particular in the proper name, and every name is originally a proper name), being is always already presupposed by language to language. As Hegel was to understand perfectly, the precedence that is in question here is not chronological but is an effect of linguistic presupposition.” (2015: p.129)

10 This is not strictly accurate. Caesar was in fact a cognomen, a (part of a) family name. What is important, however, is that in a particular context, "Caesar" picks out a single person. This is the typical feature of almost all proper names. They are usually not exclusive (there are many Johns and Smiths). Proper names can, however, refer to a single person in a particular context. 11 This happened in $69 \mathrm{AD}$ with the end of the reign of the Julio-Claudian dynasty. 
a property or role). The particular moment can be taken as a paradigm (Hegel writes that Caesar "may be adduced as a paragon [Muster] of Roman adaptation of means to ends [Zweckmäßigkeit]" (LPH: p.285; PGh: p.379)). Caesar's military and political career is the paradigmatic case of a person who is called an emperor (a caesar with lowercase c) or-in other words-a caesar (with lowercase c) is a person who is such that their political position is similar or comparable to Caesar's (with a capital C). One final remark before we proceed to the next example: as has already been made clear, the passage from individuality to universality is marked by a series of negations. Hegel stresses that the judgement "the individual is universal" expresses "both the perishableness of singular things and their positive subsistence in the concept in general” (SL: \$1364). Caesar as an individual had to perish in order to be transformed into a universal concept and to subsist as such (cf. Žižek 2012: p.455). His physical death triggered this transformation. This aspect becomes even more central in the next example.

\section{Jesus}

From his early works to his last lectures, Hegel devoted many pages to the life of Jesus and to Christianity. This example is more complex than the previous one, because it is rich in dialectical moments. I would like to begin in the middle with the moment of particularity. In his very early writings from 1793, published as Notes for a Folk Religion, Hegel maintained that Jesus is a model [Muster] and an ideal of virtue. This is so because Jesus has a supplement of the divine [Beimischung, Zusatz das Göttlichen] (FS: p.83). Otherwise, he would be only an example of a virtuous man like Socrates. Jesus thus had both a divine and a human nature. Hegel sees this double nature as Christianity's crucial advantage over the abstractness of older religions and ethical conceptions which neglected the moment of particularity. ${ }^{12}$ Moreover, Jesus was "a perfect man, [who] endured the lot of all men” (LHP III 1896: p.5; GP II: p.526). Jesus, by the way he lived and died, thus stands for all men. He is the paradigm of a (Christian) man. ${ }^{13}$

12 This neglect of the moment of particularity or of the paradigm can be illustrated by the example of Stoicism. The ideal of Stoic virtue, the sage, was an extrapolated, i.e. abstract ideal, not a man of flesh and blood like Jesus. The concrete, paradigmatic sample is absent in Stoicism. Hegel quotes Cicero in this connection: "But who this wise man is or has been the Stoics never say” (LHP II 1894: pp.250-1; GP II: p.269; Academicae questiones IV, 47).

13 This indicates that the example conception of particularity is inadequate, to say the least. Jesus is neither an example of a virtuous man nor an example of God. 
If we follow the development of the concept of God, then the universality of God the Father is particularised in Jesus, the Son, and finds its final stage in the individuality of the Holy Spirit. The Christian Trinity thus follows the three moments of the development of the concept (cf. Stewart 2011: p.509). The Holy Spirit is for Hegel "the universal self-consciousness of a religious community, [... it] is the universal self-consciousness [...], the individual together with the consciousness of the religious community” (PS 2018: \1763). The Holy Spirit thus demonstrates the moments of both (concrete) universality and individuality. The passage from Jesus Christ to the Holy Spirit can be taken as the passage from particularity to universality-or as the judgement from the individuality of God the Father to the particularity of Jesus Christ and finally to the universality of the Holy Spirit. Now, Jesus is the negation (the first negation) of God the Father, and the Holy Spirit is the negation (the negation of the negation of God the Father) of Jesus. Let us focus on the second negation, i.e. the negation of the negation. This negation of the negation, or the death of death, has two moments: on the one hand, it is the death of the manifested God: "Christ dies; [but] only as dead, is he exalted to Heaven and sits at the right hand of God; only thus is he Spirit. He himself says: 'When I am no longer with you, the Spirit will guide you into all truth.”' (LPH III 1896: p.14; PGh: p.393) The physical death of the particular individual, of Jesus Christ, is necessary for its transition into the universality of the Spirit. This is analogous to the death of Caesar, after which "its spiritual and inward existence was unfolded under Augustus" (PGh: p.385). Hegel clearly recognises this analogy when he opens the section "Christianity" in his Lectures on the Philosophy of History. On the other hand, the negation of the negation is the negation of this death; it is the death of death. It is God's preservation; through his resurrection, God rises into life again. Curiously enough, Hegel maintains that Christ's human nature is also preserved; moreover, the death of death is the highest preservation and elevation of his human nature (Rel II: p.291).

\section{Negation and reflexivity}

A negation of the particular involves a negation of its individual moment. Caesar or Jesus had to die in order to pass over into the concrete universality. If the particular moment is a paradigm, then its individual moment is a paradigmatic sample. Hegel thus maintained that the paradigmatic sample has to disappear. This position does not seem very plausible. For instance, the standard metre does not need to be destroyed in order to establish the metre as the universal unit of length. Quite the contrary! The standard metre must be preserved, for it must 
be available to compare with other objects. This praxis constitutes the universal unit. A paradigmatic sample is a prototype which can be copied, but this does not result in the sample being destroyed. How can we thus make sense of Hegel's position?

The paradigmatic sample of $\mathrm{X}$ can be used to produce concrete instances of $\mathrm{X}$. These instances make up the concrete universal. We can ask, however, whether the paradigmatic sample of $\mathrm{X}$ is an individual part of this concrete universal. Is the paradigmatic sample of $\mathrm{X}$ an $\mathrm{X}$ ? Is the standard metre one metre long? Was Caesar a caesar? Such questions are, however, paradoxical. Wittgenstein says: "There is one thing of which one can state neither that it is 1 metre long, nor that it is not 1 metre long, and that is the standard metre in Paris.” (PI: §50) He makes analogous claims about other paradigmatic samples. Hence, we cannot decide whether the paradigmatic sample of $\mathrm{X}$ is a part of $\mathrm{X}$. If one cannot say that the standard metre is one metre long then this combination of words has no sense. Such "a combination of words is being excluded from the language, withdrawn from circulation” (PI: §500). This structure of the paradigmatic sample as neither in the universal nor excluded from the universal is the structure of Hegel's sublation. The paradigm is not quite a part of the universal, but it is at the same time preserved in the universal. The paradigm is not an individual moment of the universal, but is its particular moment.

Following Hegel's logic, paradigmatic samples are thus destroyed in the course of the negation of negation. As a material object, it cannot be asked of the sample-deliberately or accidentally-whether it belongs to the universal concept. The sample as such is simply not there any more. We cannot confuse Caesar with a Kaiser, for this concept came into existence after Caesar's death and (we can assume) he will never come back to life. ${ }^{14}$ The situation is different with Jesus. According to Christian doctrine, he will return on Judgement Day, at the Last Judgement, and resurrect all men (including Julius Caesar). Jesus's second coming thus does not fit into Hegel's dialectics. So it is no surprise that Hegel never paid much attention to the Apocalypse and the Last Judgement in his treatment of Christianity.

14 What is left are only historical accounts of Caesar's life. Their epistemic usefulness depends on the following conditions: they must be true and we must understand the language in which they are formulated. This means that (1) someone (a historian, a witness or Caesar himself) must actually have compared facts about that time with paradigmatic samples and written down the results of these comparisons (truthfulness) and (2) we must have access (albeit indirect through causal chains) to these paradigms (understandability). This is a complex issue that is beyond the scope of the present discussion. 


\section{Development of the judgement}

Let us return to Hegel's core doctrine of subjective logic. If the judgement is the posited particularity of the concept, then the judgement must be developed beyond its abstract form "the individual is a universal", which abstracts precisely from the particular moment. Hegel developed the judgement into 12 species. Let us examine how they involve the particular moment, i.e. a paradigm.

The first group comprises three judgements of quality. The positive judgement has the form "the individual is a particular", as in "the rose is red". Here an individual, this rose, is compared with the paradigmatic sample of red with respect to their colour. A positive judgement consists in their agreement in terms of colour. Of course, the rose also possesses other qualities, that is, it can be compared with other paradigmatic samples. On the other hand, there are more red objects besides this individual rose, that is, other objects are the same colour as the paradigmatic sample of red. The subject and the predicate come into contact at one point or aspect, that is, with respect to their colour. They can be different in other aspects, e.g. in their shapes, sizes, materials, etc.

The first negation of the positive judgement leads to the negative judgement. What is negated here is the agreement of the individual subject and the particular predicate, e. g. in "this rose is not red". The individual, this rose, is comparable with the paradigmatic sample of red, but they happen not to agree. This means the rose is a different colour. The individual, the rose, and the particular, the paradigmatic sample of red, belong to the same genus, i.e. objects of (a certain) colour.

The negation of this connection of comparability, of having the same genus, yields the infinite judgement. In such a judgement, there is no relation between the individual subject and the particular predicate. The individual subject is not comparable with the paradigmatic sample. Hegel's example is "the spirit is no elephant" (E I: §173). We can also add the example "the number 4 is not red". Hegel adds another example: "a lion is no table" (ibid.). A lion is, in fact, comparable with the paradigmatic table. But lions and tables are of different genera. It is reasonable, however, to keep the method of comparison, i.e. the praxis of comparing the paradigmatic table with other objects, as simple as possible, by restricting the comparison to objects of the closest genus (furniture in this case). Thus, judgements involving what is nowadays called a "category mistake" are, in Hegel's terms, infinite judgements.

Let us move on to the judgement of reflection. Here, the predicate is not "an immediate, abstract quality" (EL 1830/2010: p.248; §174) but instead what we would call a relational property. In the language of paradigms, this means 
that paradigms involve more paradigmatic samples in these cases. But these other paradigmatic samples are not determined in a judgement of reflection. Hegel's example, "this plant has healing powers", shows this. This sentence does not express what healing powers are meant (which illness, what dosage, any contraindications, etc.). The predicate is, thus, both an abstract universal and something particular. This abstract universal must be fixed by another judgement. The judgement of reflection thus already points towards a higher structure, namely the syllogism.

In the singular judgement, the individual subject is equated with the abstract universal predicate. The predicate is also something particular. It is a paradigm relating more paradigmatic samples with the individual in the subject position. This individual, as it were, fills one slot in the paradigmatic praxis, but there are other slots still to be filled.

The particular judgement has the same predicate as the singular judgement, but the subject is something particular, as in "some plants have healing powers". The subject can be the same individual as in the singular judgement, but what matters are some of its particular properties determined by a paradigm (of a plant). Any paradigmatic sample has many properties beyond the property it is the paradigm of. For example, the paradigmatic sample of red has a colour (i.e. red), but it also has a shape, a size, a weight, a porosity, a chemical structure, etc., but these properties are not taken into account in its paradigmatic application. In the particular judgement, however, some of these properties do enter the judgement. In "some roses have healing powers", the chemical structure of this or that rose is being compared with the paradigm of healing powers. But in the paradigm of a rose, the chemical structure does not matter (or at least let us assume it does not). In the particular judgement, the particularity of the subject is different from the particularity of the predicate.

This difference is negated in the universal judgement. Here, the subject must be something particular, that is a paradigm, and the predicate is again an abstract universal, but also a paradigm involving more paradigmatic samples. But unlike the particular judgement, these two paradigms pick out properties within the same aspect. In the judgement "all predatory animals are dangerous", what makes an animal predatory is the same feature that makes it dangerous (and it remains undetermined how exactly they are dangerous). The universal judgement is a relation between two compatible paradigms with respect to properties they pick out and thus expresses a kind of necessity. This leads to the judgement of necessity.

The judgement of necessity addresses the substance or nature of the subject. Unlike the universal judgement, the predicate is a concrete universal, that is a universal posited in its particularity. In the categorical judgement, the subject 
is something particular (e.g. "gold") or something individual posited in its particularity ("Gaius"). Such a particular is a paradigm, which consists of, as we know, a paradigmatic sample together with a praxis that is its method of application. This paradigm embraces the paradigmatic praxis of the concrete universal predicate. There is a partial identity between these two paradigms, not only between abstract properties they pick out as in the universal judgement. For instance, in "gold is metal", the paradigm of metal is a part of the paradigm of gold (e.g. "gold is a metal that has atomic number 79").

The hypothetical judgement expresses a necessary relation between two concrete universals posited in their particularities, that is, between two paradigms: “'If A is, then B is'; or 'The being of A is not its own being but the being of another, of B."' (SL 2010: p.576) The necessity of this relation comes from its partwhole character (like in the categorical judgement). What is not determined in either the categorical or the hypothetical judgement is the form of the connection between the subject and the predicate. ${ }^{15}$ The being of $\mathrm{A}$ is some or any part of the being of B. Being metal is a part of the nature of gold.

In the disjunctive judgement, this under-determinacy of form is negated. The subject is a concrete universal; the predicate is a disjunctive totality of determinations of this universal. In other words, the particularity of the universal is identical to the disjunctive totality of several particulars. "A is either B or C or D." The paradigm of $\mathrm{A}$ is nothing but an application of the paradigms $\mathrm{B}$ or $\mathrm{C}$ or D (consecutive, in any order). Hegel stresses that these particularities are mutually exclusive and that they exhaust the concrete universal. In the disjunctive judgement, the copula expresses a genuine identity. The judgement emerges, for the first time, as Ur-teil, that is, "original or primordial division" of a concept. The disjunctive judgement expresses the identity of the universal and the particular; in other words, it defines the universal as a combination of (mutually exclusive) paradigms.

What is missing in the disjunctive judgement is the moment of individuality. This is remedied in the judgement of concept. In the assertoric judgement, the subject is a concrete individual that is related to its general concept, which identifies the individual subject. The predicate expresses this identification. In the judgement "this house is good", an individual house is determined as such, as a house; and it is good as a house (and not as an artwork, for example). We can thus interpret the judgement as "this house is a good house". The asser-

15 The progression from the categorical to the hypothetical judgement lies exactly in this underdeterminacy: "Thus, for example, the gold is indeed metal, but silver, copper, iron, and so forth are likewise metals, and being metal as such behaves indifferently to the particular character of its species.” (EL 1830/2010: p.251; §177) 
toric judgement thus expresses the unity between the individual and its concept (its universal nature mediated by the particular that is expressed in the predicate). The individual is compared with the paradigm of the universal concept and the judgement expresses their fit. This house is compared with the paradigmatic house and their good fit or agreement is expressed in the judgement "this house is good".

The individual in the subject position, this house, is, however, something contingent. A house is designed, built, used, repaired, used again and eventually demolished. These are its moments, which are contrasted with the universal nature of its concept, the house. Hegel calls this the subjectivity of the thing or its negativity. ${ }^{16}$ This contingency is expressed in the problematic judgement. This house is good, perfect, beautiful, etc. only in a certain stage of its life cycle. This house may or may not agree with its original design (what this house was supposed to be, its ought). This design agrees with the paradigm of the house (otherwise it would not be a design of a house, but of something else, e.g. a car).

In the apodictic judgement, the individual subject is given with its particular character (Beschaffenheit) and identified with a universal concept. The subject is thus a concept in all three of its moments, individuality, particularity and universality. The predicate expresses their agreement, that is the unity of this concept. In the judgement "this house so and so constituted is good", the individual referred to as "this" agrees with the paradigmatic house "so and so constituted" and for this reason, it is a "good house". The fact that this house agrees with the paradigmatic house in such and such a way is not the object of the judgement, but rather its presupposition. Even the apodictic judgement is true or false within a larger context, which is addressed by Hegel under the heading "syllogism" (Schluß).

16 WL II: p.348: "Das Problematische des Subjekts an ihm selbst macht seine Zufälligkeit als Moment aus, die Subjektivität der Sache, ihrer objektiven Natur oder ihrem Begriff gegenübergestellt, die bloße Art und Weise oder die Beschaffenheit.” Di Giovanni renders "die Subjektivität der Sache" as "the subjectivity of the fact" and "Beschaffenheit" as "constitution". "The problematic element in the subject itself constitutes its moment of contingency, the subjectivity of the fact it expresses as contrasted with its objective nature or its concept, its mere mode and manner or its constitution.” (SL 2010: p.584) 


\section{Interim conclusion}

Let us go back to Hegel's initial definition of the judgement: “The judgment is the concept in its particularity as the differentiating relation of its moments, which are posited as being for themselves and, at the same time, as identical with themselves, not with one another." (EL 1830/2010: p.240; §166) The judgement is a relation within the concept between two of its moments, e.g. between the individual and the particular in the positive judgement. If we take the particular as a paradigm, we can attempt a bolder interpretation: the particular moment, a paradigm, is involved in every judgement, i.e. in every relation within a concept, and the twelve forms of judgement comprise the complete list of paradigmatic cases of this involvement. Even if we take the judgement in its abstract form, that is, where the individual is the universal, which seemingly does not involve the moment of particularity, its extremes, the subject and the predicate, can be related only through the particular, that is, through a paradigm, and they, in fact, develop into their particular moments-as we have seen in the examples of Caesar and Jesus. The demand of the judgement is thus that the individuality/singularity and the universality must be mediated through the particularity, $\mathrm{S}-\mathrm{P}-\mathrm{U}$, which is the Schluß.

\section{Schluß in general}

Hegel famously maintained that everything is a Schluß. "Schluß" is usually rendered into English as inference, syllogism or syllogistic inference, which I believe already favours certain interpretations of Hegel's subjective logic. That everything is an inference has become a key claim of "semantic" interpretations of Hegel, and of Brandom's inferentialism in particular. In this paper, I keep the term "Schluß" in the original German in order to preserve the aspect of its meaning relating to completion or realisation (of the concept in objectivity). My aim is to provide an alternative interpretation of subjective logic that does not focus on the notion of inference or on language or semantics in general. On the other hand, I do not want to adopt the traditional full-fledged metaphysical interpretation (mostly because I simply do not address parts of Hegel's system other than his subjective logic). I shall provisionally call my interpretation "epistemic". Let me briefly mention two key passages that fuel my interpretation. Firstly: Hegel's remark in the Encyclopaedia that "Everything is a syllogism". Secondly, in the Science of Logic, where he writes: 
All things are a syllogism [Alle Dinge sind der Schluß], a universal united through particularity with singularity; surely not a whole made up of three propositions. (SL 2010: p.593)

Hegel says explicitly that to be a Schluß means that a thing is a unity of a universal through particularity with singularity. A Schluß is each thing's unity of the three conceptual moments. An expression of this unity in language as consisting of three propositions is, I claim, an epiphenomenon. ${ }^{17}$

\section{Development of the Schluß}

The judgement is a unity of two conceptual moments. The Schluß is a unity of all three moments: individuality, particularity and universality. That is why Hegel claims that the Schluß "is the completely posited concept; it is, therefore, the rational" (SL 2010: p.588). The Schluß can be expressed in the language of informal logic (which I take to be epiphenomenal) as follows:

$A$ is $B$.

$\mathrm{B}$ is $\mathrm{C}$.

$\mathrm{A}$ is $\mathrm{C}$.

In its abstract form, the Schlu $\beta$ is a connection of term A with term C mediated by term B:

$$
\mathrm{A}-\mathrm{B}-\mathrm{C}
$$

$\mathrm{A}$ and $\mathrm{C}$ are the extremes and $\mathrm{B}$ is the middle term which mediates between them. Let us now look at the development of the Schluß and its figures. In the Schlu $\beta$ of existence, the terms are determined in isolation. The general schema of the first figure is

$$
\mathrm{S}-\mathrm{P}-\mathrm{U}
$$

Singularity is connected with universality through particularity. On my interpretation, this means that a singular object is subsumed under a universal quality by virtue of being compared with a paradigmatic sample. An object is subsumed

17 The same is true of a judgement which applies to things as well. Hegel talks for instance about the judgement of a plant (see above). 
under the universal quality "to be one metre long" by virtue of being compared with the standard metre and having the same length. Or an object is subsumed under the universal quality "(to be) sepia” by virtue of being compared with the paradigmatic sample of sepia and having the same colour.

Yet the two connections, $\mathrm{S}-\mathrm{P}$ and $\mathrm{P}-\mathrm{U}$, are supposed to be mediated too. The first figure thus refers to two other figures:

$$
\begin{aligned}
& \mathrm{P}-\mathrm{S}-\mathrm{U} \\
& \mathrm{S}-\mathrm{U}-\mathrm{P}
\end{aligned}
$$

In the second figure, the connection between the particularity and the universality is mediated by the singularity. This means that the paradigm must also be a singular object that is subsumed under the universal quality. ${ }^{18}$ In the third figure, the connection between the singularity and the particularity is mediated by the universality. This means that in comparing a singular object with a particular paradigmatic sample, a universal category is presupposed. In our two examples, the categories of length and colour are presupposed when an object is compared with the standard metre or the standard sample of sepia (this point is made by Wittgenstein in his critique of the immediacy of the ostensive definition; cf. my discussion of this idea above).

Let us briefly turn to consider the mathematical Schluß, where the moment of particularity is not explicitly mentioned. The abstract form of this Schlu $\beta$ is U-U $-\mathrm{U}$. If universal $\mathrm{A}$ is equal to universal $\mathrm{C}$ and $\mathrm{B}$ is equal to universal $\mathrm{C}$, then $\mathrm{A}$ is equal to B. The other moments are, however, implicit in this Schluß: if two particulars or two singular things are equal to a third one, then they are equal to each other.

Next, I move on to the Schluß of reflection, where the middle term is posited in its totality. The Schluß of reflection is an explicit elaboration of the judgement of reflection, where the singular subject implicitly assumes a genus (SL 2010: p.609) and where the predicate is a relational property involving two paradigmatic samples. In this Schluß, this relation is contained in the middle term. More explicitly, the middle term now contains: "(1) singularity; (2) but singularity expanded into universality, as an 'all'; (3) the universality that lies at the basis, uniting singularity and abstract universality in itself, the genus.” (SL 2010: p.609)

18 This is a questionable claim for Wittgenstein (but not for Hegel). The point of $\S 50$ of Wittgenstein's Philosophical Investigations is that we cannot say that a paradigmatic sample has (or does not have) the quality of which it is the paradigm. We cannot say of the standard metre that it is (or is not) one metre long. 
The first figure is the Schlu $\beta$ of allness, which has the abstract form S-P-U. The middle term is an abstract particularity, i.e. all singulars of a certain kind: "all humans", "all green things", "all regular things"; it is a totality of all concrete things that share a certain property, but that have other properties besides that. The major premise states that these singulars have some other universal property: "mortal", "pleasing", etc. The minor premise states that a singular (e.g. Gaius) belongs to the alls picked up in the major premise. The conclusion just states that this singular has the universal property predicated in the major premise ("Gaius is mortal"). This means, however, that the conclusion (S-U) must already be contained in the major premise $(\mathrm{P}-\mathrm{U})$. Therefore, the subject and the predicate are connected immediately in the conclusion. The major premise is a universal judgement (e.g. "All humans are mortal"). This judgement involves, as we know, a relation between two compatible paradigms with respect to properties they pick out. But here, unlike in our analysis of the universal judgement, the necessity is not guaranteed by picking out compatible properties, but is mediated by the totality of the middle term. So, for example, we may find out that all regular buildings are beautiful, but we do not define regular things by their being beautiful (we do not compare an individual with the paradigmatic sample of a regular thing with respect to their beauty, but rather with respect to their shapes or other geometrical properties).

The major premise is, in fact, mediated by a totality of singulars. This brings us to the Schluß of induction, which has the general schema U-S-P. The middle term is the totality of all singulars that have some property in common, which is the one extreme (U). The other extreme $(\mathrm{P})$ is the immediate genus or the subject of the universal judgement. The Schlu $\beta$ proceeds as follows: we discover that singulars that are A are also B. We can, so to speak, take the paradigm of B as the necessary condition of being A. For instance, we may find out, by empirical induction, that all animals that are predatory are also dangerous. This may lead us to augment the paradigm of a predatory animal with the property of being dangerous.

In the Schluß of analogy, $\mathrm{S}-\mathrm{U}-\mathrm{P}$, the middle term is a concrete universality (U) of a singular thing, or "a singular taken in its universal nature" (SL 2010: p.614). The one extreme is a singular thing (S) and the other is a universal which is also the nature of the middle term (P). A singular term is subsumed under a universal that is taken as a singular further subsumed under another particular. The middle term is thus posited as a singular in the one premise and as a universal (of this singular) in the other. But this relation between the singularity and its universal nature must be mediated by a particular, by a paradigm. In Hegel's example, the first premise is "The moon is an earth". "Earth" is here posited as a universal. In the second premise, "The earth is inhabited", 
"earth" is a singular that is subsumed under the particular "inhabited". Now the relation between the singularity and the universality in the first premise must also be mediated by a particular, by a paradigm. The two mediations are the same. The moon is an earth by virtue of being compared with the paradigmatic earth; and the paradigmatic earth is inhabited by virtue of being compared with the paradigm of being inhabited. Therefore, the moon is inhabited too. Of course, this conclusion holds only if these two paradigms share the same genus (i.e. if being inhabited belongs to the nature of the earth).

The Schluß of necessity proceeds by further determining the middle term, which is posited as a concrete universal, that is, as a universal in its particularity, as the universal nature of a thing, its genus. The first figure is the categorical Schluß, which has the categorical judgement for one or both of its premises (SL 2010: p.618). As we already know, the categorical judgement expresses a relation of subsistence between two paradigms (one is part of the other). The other extreme is a singular whose general nature is captured by the middle term. So, for instance, we may say that "This ring is gold" and "Gold is a metal", which leads to the conclusion that "This ring is metal(lic)". The categorical Schluß can have two categorical judgements as its premises. Then it is just a relation of three paradigms, A is B, B is C, ergo A is C. For instance, "Gold is a metal", "Metals are chemical elements", ergo "Gold is a chemical element".

The general scheme of the hypothetical Schlu $\beta$ is U-S-P. The one premise is a hypothetical judgement, "If A is, so is B", the other is the being of A. The hypothetical judgement expresses a necessary relation between two concrete universals posited in their particularities, that is, between two paradigms: one is a part of the other. In the hypothetical Schluß, this necessary relation is only one extreme mediated by the being of A to the other extreme, the being of B. Hegel concludes that A and B "are two different names for the same basic thing” (SL 2010: p.621). But other things can also be B that are not A (this comes from the underdeterminacy of the hypothetical judgement, where the form of the connection between the subject and the predicate remains indeterminate).

This indeterminacy is sublated in the disjunctive Schlu $\beta$. The major premise is a disjunctive judgement, “A is either B or C or D ...”. The subject A is a concrete universal, the predicate is its total determination, i.e. a consecutive application of paradigms. The minor premise "But A is B" / "But A is neither C nor D ..." is a further positive or negative determination of $\mathrm{A}$. The conclusion is the remaining negative or positive determination of A, "Therefore A is neither C nor D ..." / "Therefore A is B". Hegel says that the disjunctive Schlu $\beta$ "is in general in the determination of universality" (SL 2010: p.623). The universal concept A is further determined as $\mathrm{B}$ and neither $\mathrm{C}$ nor $\mathrm{D}$. This can be read in two ways: the disjunctive judgement of $\mathrm{A}$, i.e. the complete determination of $\mathrm{A}$ is further determined 
by the minor premise, which may be a result of some experience. One knew that this object is coloured and now comes to know that it is red (and neither blue nor green). Another way of understanding the disjunctive Schluß is that it opens up the possibility of combining determinate concepts, i.e. paradigms, into more general concepts. The particular concepts B, C and D-given that they are mutually exclusive and pick out the same general aspect-can be combined into the more general concept A.

\section{Conclusion}

Hegel writes at the end of the section "Subjectivity" in the Science of Logic that the Schluß is the realisation of the concept and that with the Schluß, the concept has gained objectivity (SL 2010: p.624). I began the previous section with the crucial claim that each thing is a Schluß. I understand Hegel's discussion of the ten forms of the Schlu $\beta$ as a kind of proof of this claim, which can now be taken as the claim that what makes up an object is the unity of the singularity and the universality mediated by the particularity. The moment of particularity has a mediating role between the individual and the universal. This is also the role of the paradigm. A paradigm-again taken as a paradigmatic sample together with the method of its application or comparison-is something that defines a universal class and, at the same time, is related to individual elements of this class (via the method of comparison). The general thesis lingering in the background is that we cannot do without paradigms in our epistemic practices. Hegel advanced this thesis by insisting on the moment of particularity. Wittgenstein provided an implicit argument that concepts that are not rooted in our practices with external objects are, in fact, private practices and thus epistemically defective. ${ }^{19}$

\section{References}

Agamben, Giorgio: The Use of Bodies: Homo Sacer IV, 2, Stanford University Press, 2015. Badiou, Alain: Saint Paul: the Foundation of Universalism, Stanford University Press, 2003. Houlgate, Stephen and Baur, Michael: A Companion to Hegel, Blackwell, 2011.

19 I would like to thank Paul Redding for helpful comments and the participants of the conferences Wittgenstein and Hegel: Reevaluation of Difference (Dresden, June 2017) and Themes from Hegel's Science of Logic (Istanbul, October 2018) for a stimulating discussion. This work has been supported by the Czech Science Foundation, project no. GA19-16680S. 
Mácha, Jakub: Wittgenstein of Internal and External Relations: Tracing All the Connections, Bloomsbury, 2015.

Redding, Paul: “The Role of Logic 'Commonly So Called' in Hegel's Science of Logic”, British Journal for the History of Philosophy 22:2, 2014: 281-301.

Stekeler-Weithofer, Pirmin: Hegels analytische Philosophie. Die Wissenschaft der Logik als kritische Theorie der Bedeutung, Ferdinand Schöningh, 1992.

Stewart, Jon: "Kierkegaard and Hegel on Faith and Knowledge", in: Houlgate and Baur 2011: pp.501-518.

Warminski, Andrzej: Readings in Interpretation. Hölderlin, Hegel, Heidegger, University of Minnesota Press, 1986.

Winfield, Richard Dien: From Concept to Objectivity: Thinking Through Hegel's Subjective Logic, Routledge, 2006.

Winfield, Richard Dien: “Hegel's Solution to the Mind-Body Problem”, in: Houlgate and Baur 2011: pp.227-242.

Žižek, Slavoj: Less than Nothing: Hegel and the Shadow of Dialectical Materialism, Verso, 2012. 